\title{
Análise da qualidade das calçadas públicas de Maringá: garantindo o direito de ir e vir do idoso no ambiente urbano*
}

\author{
Analysis of Maringa's public sidewalks \\ quality: guaranteeing the transit of elderly \\ people in urban environment
}

Waldir Silva Soares Junior ${ }^{1}$ Guilherme Ribeiro de Moura ${ }^{2}$ Ivania Skura ${ }^{3}$

Ana Paula Machado Velho ${ }^{4}$
* Recebido em: 16/04/2015. Aprovado em: 15/05/2015.

1 Doutorando em Matemática - UEM. E-mail: dirsoares@hotmail.com.

2 Graduando em Engenharia Civil - UniCesumar. E-mail: gui.moura21@gmail.com.

3 Mestranda em Sociedade e Desenvolvimento Unespar. E-mail: ivaniaskura@hotmail.com.

4 Profa Dra do Mestrado em Tecnologias Limpas UniCesumar. E-mail: anapaula.mac@gmail.com.

\section{Resumo}

Esta pesquisa discute o fato de que, assim como em outros locais do Brasil, as calçadas de Maringá-PR apresentam falta de qualidade, quando são analisadas com base nas determinações da ABNT NBR ISO 9000/2005, colocando em risco o transeunte e o direito de ir e vir do cidadão. Chama-se atenção para a garantia da acessibilidade dos idosos nas ruas das cidades, já que este público é mais vulnerável, devido às alterações do envelhecimento. Foi feito levantamento para a apresentação de um estudo descritivo em diferentes bairros da cidade. Constatou-se que o maior problema está nos bairros, que merecem uma atenção maior dos proprietários de imóveis, além de engenheiros e arquitetos, responsáveis pelo planejamento e execução das obras residenciais. Porém, acredita-se que o principal descaso é o do poder público. Para que as calçadas da cidade tenham melhores condições, o cidadão precisa contribuir e as autoridades devem cobrar o cumprimento das leis, assim como fiscalizar a execução das obras e punir os profissionais que executam esses projetos de construção civil de forma inadequada.

Palavras-chave: Acessibilidade. Passeio público. Terceira idade.

\begin{abstract}
This research discusses the fact that, as in other parts of Brazil, the sidewalks of Maringá-PR have poor quality when are analyzed due to the determination of ABNT NBR ISO 9000/2005, endangering the passer and the right of movement of citizens. Attention is drawn to guarantee the accessibility of the elderly on city streets, as this audience is more vulnerable due to aging changes. A survey to present a descriptive study in different districts of the city was made. It was found that the biggest problem is the neighborhoods that deserve greater attention of homeowners, as well as engineers and architects, responsible for the planning and execution of residential construction. However, it is believed that the main neglect is the government. For the city to have better conditions in their sidewalks citizen needs help and authorities must charge the enforcement of laws, as well as supervise the execution of the works and punish those professionals who run these construction projects inappropriately.
\end{abstract}

Keywords: Accessibility. Public Footpath. Elderly. 


\section{Introdução}

As calçadas de uma cidade (passeios públicos) são objetos de estudos de várias áreas como a Engenharia Civil, a Arquitetura e Urbanismo, e até mesmo o Direito e a Sociologia, pois são de fundamental importância para a segurança da circulação dos indivíduos na zona urbana.

É de responsabilidade da engenharia civil e da arquitetura, mas também daqueles que lidam com o espaço urbano como bem comum, pensar e discutir as formas de projetar ambientes de modo que todos tenham acesso, irrestritamente à segurança e conforto, seja em ambientes fechados ou não. Em particular, as calçadas e passeios públicos devem ser projetados de forma que atendam às necessidades de todos os cidadãos.

Segundo o conceito do Código de Trânsito Brasileiro, Lei n. 9.503, 1997, define-se como calçada: "parte da via, normalmente segregada e em nível diferente, não destinada à circulação de veículos, reservada ao trânsito de pedestres e, quando possível, à implantação de mobiliário, sinalização, vegetação e outros fins" (BRASIL, 2013).

O Ipea - Instituto de Pesquisa Econômica Aplicada, do Ministério de Planejamento, Orçamento e Gestão, publicou uma síntese dos resultados da pesquisa "Impactos Sociais e Econômicas dos Acidentes de Trânsito nas Aglomerações Urbanas", realizada pelo Instituto, em conjunto com a ANTP - Associação Nacional de Transportes Públicos, que incluiu um levantamento de quedas e tropeços de pedestres, sem o envolvimento de veículos, ocorridos na calçada ou na via. A pesquisa realizada na Aglomeração Urbana de São Paulo revelou nove quedas por grupo de mil habitantes, a um custo médio em torno de R\$2,5 mil por queda (GOLD, 2003).

Visto os altos custos que uma queda causa aos cofres públicos, bem como as implicações sobre a qualidade de vida dos envolvidos, há necessidade das políticas públicas atentarem-se para a redução das barreiras arquitetônicas, especialmente as calçadas irregulares, com o intuito de diminuir a ocorrência de quedas e, consequentemente, os gastos (BECK et al, 2011, p. 285).

Principalmente, num momento em que o número de idosos na população se mostra como fenômeno demográfico de maior destaque no Brasil e no mundo coloca-se cada vez mais em pauta essa discussão ${ }^{5}$.

5 "De acordo com a previsão da Organização Mundial de Saúde, em 2025, o Brasil será o $6^{\circ}$ país do mundo em número

\section{A questão do idoso}

Como já elucidado, o Brasil e o mundo têm de se preparar rapidamente para um futuro em que o idoso será muito mais presente socialmente do que hoje, pois essa realidade é mais próxima do que se pode imaginar. Os números mostram que, como no resto do mundo, a população brasileira está envelhecendo.

Os números mostram que, como no resto do mundo, a população brasileira está envelhecendo: "a afirmação de que o Brasil é um país jovem já não corresponde por completo à realidade [...] uma vez que a relação de idosos para cada 100 jovens no país passou de 28,1 (1997), para 31,7 (2001) e 42,5 (2010)".

"Em 1980, metade da população tinha menos de 20 anos de idade, e, apenas um quarto, idade superior a 36 anos" (MESQUITA, 2012, p. 42). "O índice de envelhecimento, que expressou a razão entre as faixas etárias de 65 anos ou mais e de zero a 14 anos, se elevou cinco pontos entre 1940 e 1980, mas subiu dezesseis pontos entre 1980 e 2010" (MESQUITA, 2012, p. 43). Estão aí provas de que o Brasil é um país em envelhecimento, assim como o resto do mundo.

Estimativas indicam que os países com as maiores populações de idosos corresponderão a países em desenvolvimento. Neste contexto, o Brasil vem apresentando um dos mais expressivos e rápidos processos de envelhecimento populacional de que se tem registro. A perspectiva é de que já em 2025 os idosos no Brasil corresponderão à $6^{\mathrm{a}}$ maior população de idosos do mundo (BENNEMANN et al, 2012, p. 30).

No Brasil, "São Paulo é o Estado com o maior número de idosos: 5,4 milhões. Em seguida, vem Minas Gerais, com 2,6 milhões, e Rio de Janeiro, com 2,4 milhões" (NANÔ, 2012, p. 1). O Rio de Janeiro é a unidade da federação em que o grupo da terceira idade é mais expressivo em relação à população total [...] a cidade do Rio de Janeiro atrai idosos por oferecer "muitas amenidades, espaços públicos e bons serviços de saúde" (NANÔ, 2012, p. 1).

A projeção do IBGE (2010) é de que, no ano de 2050, o número de idosos brasileiros chegue a 30\% da população do país. E, no cenário maringaense, segundo

absoluto de pessoas idosas" (MASSUDA; COSTA, 2012, p. 69). E, "o número de brasileiros acima de 65 anos deve praticamente quadruplicar até 2060 , confirmando a tendência de envelhecimento acelerado da população já apontada por demógrafos" (BBC, 2013, p. 1). 
Carvalho (2011), já se sabe que Maringá tem cerca de 43 mil pessoas com mais de 60 anos - $12 \%$ dos 357 mil habitantes do município. Os dados mostram que a parcela da população idosa no total de habitantes maringaenses está crescendo, acompanhando movimento semelhante visto em todo o Brasil.

Tabela 1- Idosos maringaenses

\begin{tabular}{|c|}
\hline Participação dos idosos na composição da população de Maringá \\
$1990-7,3 \%$ \\
$2000-8,6 \%$ \\
$2010-12 \%$ \\
$2020-20 \%$ \\
\hline
\end{tabular}

Fonte: CARVALHO, 2011.

Como forma de atender este público, conforme ocorrem as mudanças no perfil demográfico brasileiro, são mudadas as políticas nas áreas de planejamento urbano e saúde (CARVALHO, 2011).

Sobre isso, Ramos (2013, p. 1) afirma que "a velocidade padrão instituída para os sinais verdes nas faixas de pedestres, por exemplo, nem sempre é a suficiente para que um octogenário consiga atravessar a rua”.

$\mathrm{O}$ autor aponta que a maioria dos lugares não são apropriados para acolher os idosos. As cidades devem se adaptar com urgência, já que o envelhecimento populacional é evidente. E, nesse sentido, "a experiência ajuda a perceber quais são as necessidades de intervenção mais urgentes no espaço público" (RAMOS, 2013, p. 1), isto é, no ambiente de interação social.

Analisando-se os dados acima, constata-se a importância de se investir em passeios de qualidade. Problematizam-se, então, as seguintes questões: será que as calçadas da cidade de Maringá têm qualidade? De quem é a responsabilidade de construir, preservar e garantir a qualidade das calçadas desta cidade? O que queremos saber é se essas calçadas estão com um nível aceitável de qualidade, para atender a todos os tipos de transeuntes.

Para isso, foi realizado estudo descritivo do calçamento em bairros dessa cidade, levantando-se algumas incidências de irregularidades. O objetivo consistiu em avaliar a qualidade das calçadas e utilizar os dados encontrados para apontar soluções e promover discussões acerca dos problemas identificados.

O conceito de qualidade utilizado nas avaliações foi o da ABNT NBR Isso n. 9000/2005, descrito como um conjunto de propriedades e características de um produto, processo ou serviço, que lhe fornece a capacidade de satisfazer as necessidades explícitas ou implícitas. Ou seja, não é um calçamento de qualidade se não servir as necessidades dos indivíduos tanto no conforto, segurança ou acessibilidade. Quanto às questões de conforto, destacam-se piso e largura útil da calçada e inclinação e limpeza do passeio público. No quesito segurança, podem-se citar fatores como semáforos, faixas para pedestres e veículos estacionados (LUNARO; FERREIRA, 2005).

\section{Olhando para Maringá}

Não tão antigas quanto às ruas, as calçadas foram surgindo com a necessidade de separar as trilhas de pedestres dos traçados de veículos que, em princípio, nem eram motorizados. As calçadas, também conhecidas por passeios, podem ser entendidas como caminhos que ladeiam as ruas junto às casas e que se destinam ao tráfego de pedestres (MOUETTE, 1998 apud AGUIAR, 2003).

A primeira calçada que se tem conhecimento foi construída por volta do século IV a.C. em Pompéia, na Itália. Eram pedras elevadas colocadas em intervalos regulares. Diferentemente de hoje, a função dessas calçadas era basicamente proporcionar que uma pessoa atravessasse a rua (caminho das carroças) sem contato com o esgoto, até então a céu aberto.

Já no Brasil, os passeios começaram a ser implantados no século XIX, apenas nas principais cidades brasileiras, como meio de separação e aperfeiçoamento do tráfego (REIS FILHO, 1987).

A cidade de Maringá-PR é uma cidade relativamente nova, fundada em 10 de maio de 1947. Um dos primeiros grandes problemas de uma cidade nova, em plena expansão de sua área urbana, com novos loteamentos lançados ano após ano, é a falta de passeios em frente a lotes sem construção predial. Vê-se que Maringá possui calçadas aquém do nível de qualidade que se espera para uma cidade desse porte, ou seja, a terceira maior cidade do estado do Paraná em número de habitantes.

Uma análise mais apurada mostra que o município apresenta disparidade grande entre o centro (comercial) e os bairros. Em sua grande maioria, as calçadas da área central, cujo fluxo de pedestres é altíssimo, apresentam bom estado de conservação, com rampas para acessibilidade e pisos antiderrapantes. Obviamente nada é perfeito. Algumas dessas rampas estão fora do padrão, algumas calçadas estão esburacadas, mas nada fora do aceitável.

Visitando vários bairros da cidade, porém, percebe-se grande diferença nos tipos de calçadas de uma loca- 
lidade para a outra, sendo visível a diferença de qualidade nos passeios de bairros considerados mais nobres e nos considerados mais simples, as chamadas vilas.

De acordo com a Lei Municipal n. 2158/87, do município de Maringá-PR, Art. 2: "os proprietários dos imóveis que tenham frente para logradouros pavimentados, ou com meio-fio e sarjeta, são obrigados a pavimentar os passeios à frente dos seus lotes". Porém, pode-se notar descaso dos proprietários em relação a essa lei, pois não é difícil encontrar quadras em que metade dos lotes não tenha calçamento. Isso reflete, ainda, clara falha na fiscalização.

Ainda, em virtude crescimento acelerado da construção civil em alguns bairros, o proprietário acaba fazendo a calçada com pressa, ou com descaso, ou simplesmente pela ignorância a respeito da legislação e assim a faz sem atender às normas e recomendações de construção das mesmas.

Além de toda a questão técnica sobre material a ser utilizado, distâncias, recuos, permeabilidades, uma questão de suma importância é a acessibilidade.

Segundo o Decreto n. 5.296/04, que regulamenta as Leis n. 10.048/00 e n. 10.098/00 que estabelecem normas gerais e critérios básicos para a promoção da acessibilidade das pessoas com deficiência ou com mobilidade reduzida, é proibido impedir, ou atrapalhar, por qualquer meio, o trânsito livre dos pedestres nas calçadas (CREA-BA, 2012).

Infelizmente, mesmo com toda essa normatização e legislação vigente, não estão sendo respeitados os conceitos mais simples de cidadania e acessibilidade. Existem vários obstáculos e impedimentos que dificultam que as pessoas caminhem livremente pelas calçadas de seus bairros, obrigando-as a andar pela rua, em meio ao trânsito de veículos automotores, colocando em risco sua integridade física e até mesmo sua vida. Os maiores prejudicados nesses tipos de situações são indivíduos com baixa mobilidade, como os idosos, cadeirantes, gestantes, crianças, pessoas com necessidades especiais temporárias e até mesmo uma mãe com um carrinho de bebê.

Observa-se nas Imagens 1 e 2, a falta de passeio público ao longo de vários metros que dificulta e, em alguns casos, até impede que um pedestre trafegue por ali. Já nos lugares que possuem a calçada, têm-se ainda diversos tipos de obstáculos, alguns deles impeditivos, outros
Imagem 1- Quadra praticamente inteira sem calçada

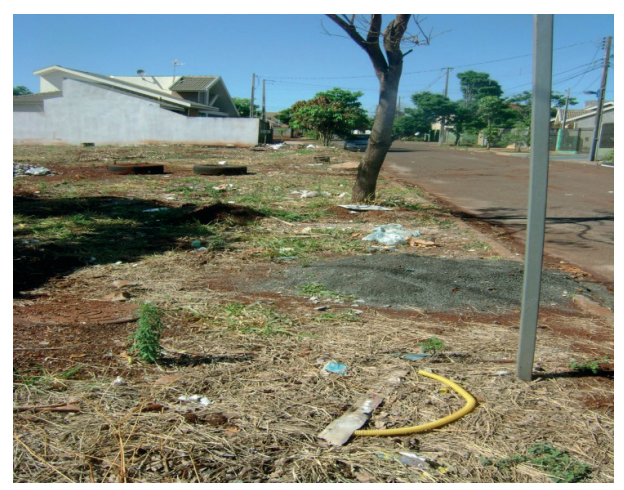

Fonte: Arquivo pessoal dos autores, 2013.

Imagem 2 - O mato cresce onde deveria ter calçada

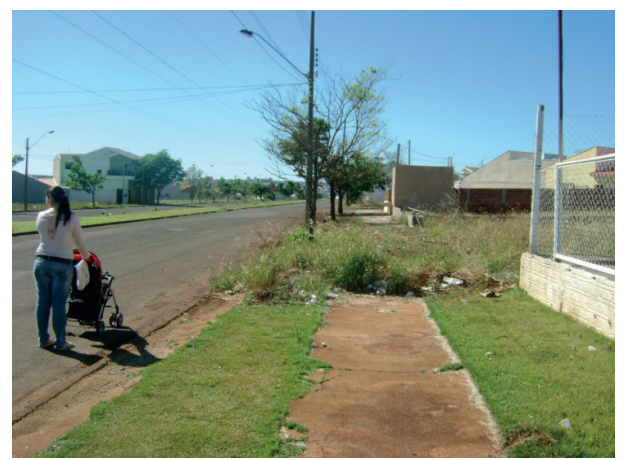

Fonte: Arquivo pessoal dos autores, 2013.

Degraus na calçada, desnível acentuado, piso escorregadio e má conservação estão entre as maiores incidências de acidentes de pedestres, que poderiam facilmente ser evitados pela construção de acordo com as normas técnicas específicas.

Observando-se a Imagem 3, podemos questionar: como um cadeirante poderia continuar seu percurso sem ser obrigado a ir para a rua? E se fosse alguém empurrando um carrinho de bebê? Ou um idoso com um andador? Observe o desnível entre os lotes vizinhos que poderia ter sido evitado no momento da construção imobiliária, ou pelo menos ter sido feita uma rampa que suavizasse a passagem.

Imagem 3 - Rampa na calçada fora de padrão

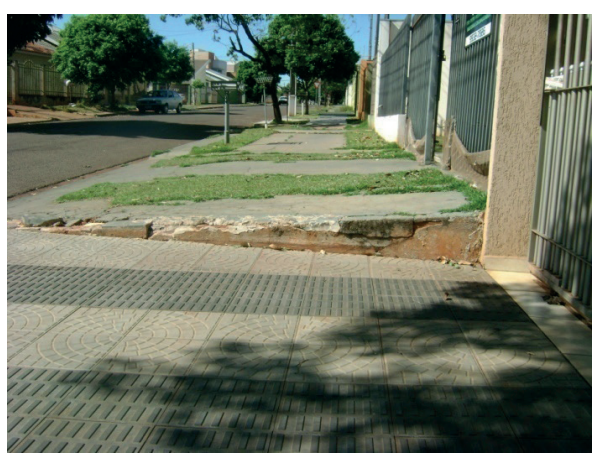

Fonte: arquivo pessoal dos autores, 2013. 
É de encargo dos engenheiros e arquitetos orientar os proprietários (leigos) em como a calçada em frente à propriedade destes deve ser construída, obedecendo às normas técnicas, leis federais e municipais.

Diante de esforços singulares que uma ou outra prefeitura vem fazendo em seu espaço público, atinente às calçadas e seus passeios relativamente à mobilidade acessível que devem prover, constata-se que há muitas mudanças ainda que devem ser idealizadas e implementadas, e que isto demanda projetos de engenharia civil para ambientes construídos, ou seja, além de exigir reestruturação, requer criatividade e visão holística do engenheiro para que a obra seja reorganizada objetivando a melhoria da acessibilidade (MIOTTI, 2012, p. 40).

$\mathrm{Na}$ Imagem 4, todo o entulho da construção foi depositado na calçada do imóvel vizinho. Primeiramente, depositar lixo ou entulhos nas calçadas e passeios é proibido e, além disso, essa ação acaba deixando uma passagem livre muito estreita para o trânsito de pedestres, bem diferente do recomendado, que é de $1,20 \mathrm{~m}$, segundo a recomendação do CREA-BA (2012).

Todas essas imagens apontam para problema de suma importância que não pode sair de pauta, já que quanto mais for discutido, maiores são as chances da visibilidade desta problemática. Os exemplos apresentados neste estudo sobre a cidade de Maringá estendem-se pelo Brasil, tendo sido relatados por Lunaro e Ferreira (2005, p. 67):

Os problemas para os pedestres idosos são inúmeros e ocorrem em diversos locais da via pública como, por exemplo, nas calçadas, que geralmente apresentam problemas como: guias e rampas irregulares; mobiliário urbano mal colocado; vegetação inadequada; piso quase sempre em péssimas condições e inadequado e tantos outros que dificultam a caminhada dos pedestres em geral, e principalmente os idosos.

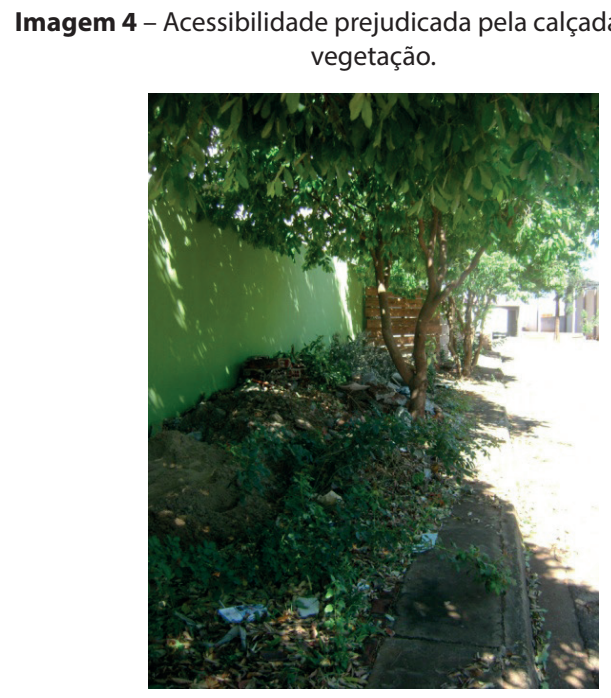

Fonte: arquivo pessoal dos autores, 2013.

\section{De quem é a responsabilidade?}

Nascimento (2010) afirma que a prefeitura tem obrigação de indenizar por queda em calçada irregular. O juiz Paulo Alexandre Ayres de Carvalho afirma que "a irregularidade da calçada deve ser atribuída ao Município por sua omissão quanto à fiscalização e conservação do passeio público, posto que deveria conservá-lo, exigir que fosse conservado ou, no mínimo, sinalizar os defeitos no pavimento" (NASCIMENTO, 2010, p. 1).

Em Maringá, a Lei Municipal n. 6509/2004, artigo $2^{\circ}$, aponta que: "se o pavimento do passeio público estiver danificado em razão da ação do tempo ou em função de sua má construção ou utilização, a responsabilidade do reparo ficará a cargo do proprietário do imóvel lindeiro".

Buza Neto (apud NASCIMENTO, 2010, p. 1) afirma que, em casos nos quais as calçadas encontram-se inapropriadas, "a omissão da Municipalidade demonstra, com clareza, a irresponsabilidade com que são tratadas as vias públicas".

A Constituição Federal brasileira de 1988 determinou como direitos fundamentais, dentre outros, a cidadania e a igualdade, Artigo $1^{\circ}$, II e III, pois a acessibilidade espacial significa a permissão para que todas as pessoas participem dos diversos espaços e atividades e, especialmente quanto aos espaços internos e externos, que deverão ser livres de barreiras a exemplo das calçadas e passeios, vias de acesso aos demais espaços públicos e privados (DORNELES; ZAMPIERI, 2008 apud MIOTTI, 2012).

Nessa discussão, chama-se atenção, especialmente, para a importância de se pensar a acessibilidade e o conforto dos idosos nas ruas das cidades. Segundo Blanco et al (2014), esse público é mais vulnerável estruturalmente ao trauma, devido às alterações do envelhecimento. Os idosos, por exemplo, apresentam capacidade reduzida de recuperação. Em caso de trauma, permanecem por mais tempo hospitalizados e perdendo gradativamente a capacidade funcional. "Mesmo que os idosos sofram as mesmas lesões que os indivíduos jovens, eles apresentam algumas diferenças a respeito, especialmente, na duração e na consequência da lesão corporal" (BLANCO et al, 2014, p. 338). Para os autores, no Brasil, entre os incontáveis desafios enfrentados pelos idosos, inclui-se a falta de planejamento das cidades, visto que neste ambiente estão os principais fatores exógenos causadores de traumas, como degraus e calçadas. 


\section{Considerações Finais}

Esta pesquisa mostrou que, assim como em outros locais do Brasil, as calçadas de Maringá apresentam falta de qualidade, quando são analisadas com base nas determinações da ABNT NBR ISO 9000/2005. Os maiores problemas estão nos bairros, onde há um fluxo de pessoas menor que no centro, mas, mesmo assim, esses problemas comprometem a mobilidade de pedestres que se expõem nas vias, concorrendo com veículos automotores.

Viu-se que os bairros merecem atenção maior dos proprietários de imóveis, além de engenheiros e arquitetos, responsáveis pelo planejamento e execução das obras residenciais.

Porém, acredita-se que o principal descaso é do poder público. Para que a cidade tenha melhores condições em seus passeios, as autoridades devem cobrar o cumprimento das leis, assim como fiscalizar a execução das obras e punir os profissionais que executam projetos de forma inadequada.

As prefeituras precisam notificar os proprietários cujas calçadas não estão de acordo com a lei, não na intenção de punir, de multar, mas sim de orientar e dar suporte necessário, mostrando que esse é um investimento para o bem-estar de todos os moradores. Também é necessário que os cidadãos cobrem o poder público, exijam fiscalização, denunciem à ouvidoria os imóveis em desacordo com essas leis.

As crianças, as pessoas com necessidades especiais (temporárias ou definitivas) e, principalmente, os idosos têm sofrido com esse problema, que, muitas vezes, passa despercebido pela maioria dos cidadãos, que costumam circular apressados pelas ruas, a maior parte em seus carros, esquecendo-se que há aqueles que dependem de uma área adequada para garantir o seu direito constitucional de ir e vir.

\section{Referências}

ASSOCIAÇÃO BRASILEIRA DE NORMAS TÉCNICAS ABNT NBR ISO 9000:2005. Sistemas de gestão da qualidade: fundamentos e vocabulário. Rio de Janeiro: ABNT, 2005.

BBC, Brasil. Número de idosos no Brasil vai quadruplicar até 2060, diz IBGE. Publicado em 29 de agosto, 2013. Disponível em: <http://www.bbc.co.uk/portuguese/noticias/2013/08/130829_demografia_ibge_populacao_brasil_lgb.shtml>. Acesso em: 10 set. 2013.
BECK, A. P. et al. Fatores associados às quedas entre idosos praticantes de atividades físicas. Revista Texto Contexto Enferm, Florianópolis, v. 20, n. 2, p. 280-62011 abr./jun. Disponível em: <http://www.scielo.br/pdf/tce/v20n2/ a09v20n2.pdf > . Acesso em: 18 out. 2013.

BENNEMANN, Rose Mari; CORTEZ, Lúcia Elaine Ranieri; YAMAGUCHI, Mirian Ueda. Promoção da saúde no envelhecimento. In: MASSUDA, Ely Mitie; VELHO, Ana Paula Machado (Org.). Promoção da saúde: um enfoque interdisciplinar. Maringá, PR: Cesumar, 2012. p. 29-40.

BLANCO, P. H. M. et al. Lesões corporais em idosos vítimas de queda no transporte coletivo. MTP\&RehabJournal, Maringá, v. 12, p. 334-348, fev./jun. 2014.

BRASIL. Constituição (1988). Constituição da República Federativa do Brasil: texto constitucional promulgado em 5 de outubro de 1988, com as alterações adotadas pelas Emendas Constitucionais n. 1/92 a 39/2002 e pelas Emendas Constitucionais da Revisão n. 1 a 6/94. - Brasília: Senado Federal, Subsecretaria de Edições Técnicas, 2003.

BRASIL. Lei 2158/87. Lei $n^{\circ} 2158$ de 06 de maio de 1987. Libera o tipo de pavimento para os passeios públicos, no município de Maringá. Disponível em: <http://cm-maringa.jusbrasil.com.br/legislacao/656329/lei-2158-87>. Acesso em: 17 ago. 2013.

BRASIL. Lei Ordinária de Maringá/PR, $n^{\circ}$ 6509/2004 de 26/03/2004. Responsabilidade pelo reparo do passeio público. Vereador Mário Hossokawa. Disponível em: <https://www.leismunicipais.com.br/a/pr/m/ maringa/lei-ordinaria/2004/650/6509/lei-ordinaria-n-6509-2004-dispoe-sobre-a-responsabilidade-pelo-reparo-do-passeio-publico-nos-casos-que-especifica-2004-03-26.html>. Acesso em: 17 jul. 2013.

BRASIL. Presidência da República. Casa Civil. Subchefia para Assuntos Jurídicos. Lei n. 9.503, de 23 de setembro de 1997. Código de Trânsito Brasileiro. Disponível em: $<$ http://www.planalto.gov.br/ccivil_03/leis/19503.htm> Acesso em: 13 set. 2013.

CARVALHO, Luiz de. Número de idosos cresce e exige novas práticas sociais. Publicado em $\mathrm{O}$ Diário.com em 11/12/2011. Disponível em: <http://maringa.odiario. com/maringa/noticia/519844/numero-de-idosos-cresce-e-exige-novas-praticas-sociais/>. Acesso em: 26 out. 2013.

CONSELHO REGIONAL DE ENGENHARIA E ARQUITETURA CREA - BA. Guia prático para a construção de calçadas. Bahia, 2012. Disponível em: <http://www. creaba.org.br/Imagens/FCKimagens/12-2009/Guia_Pratico_web_Construcao_de_Calcadas_CREA.pdf $>$. Acesso em: 16 ago. 2013. 
GOLD, Phillip. Calçada adequada: respeito à cidadania. Pérgamo Engenharia. 2003. Disponível em: <http://pergamoengenharia.eng.br/615/29712.html\#top $>$. Acesso em: 26 out. 2013 .

INSTITUTO BRASILEIRO DE GEOGRAFIA E ESTATÍSTICA IBGE. Pesquisa nacional por amostra de domicílios. 2010. Disponível em: <http://www.ibge.gov.br/ home/presidencia/noticias/noticia_visualiza.php?id_noticia $=2125 \& i d \_p a g i n a=1>$. Acesso em: 24 fev. 2013.

LUNARO, Adriana; FERREIRA, Marcos Antonio G. Os espaços públicos e a questão da acessibilidade sob o ponto de vista dos idosos. Ciência \& Engenharia (Science \&EngineeringJournal), v. 15, n. 2, p. 67-72, 2005. Disponível em: <http://www.seer.ufu.br/index.php/cieng/article/ view/547/2691>. Acesso em: $12 \mathrm{dez} .2013$.

MASSUDA, Ely Mitie; COSTA, Cássia Kely Favoretto. Envelhecimento da população brasileira e o sistema único de saúde. In: MASSUDA, Ely Mitie; VELHO, Ana Paula Machado (Org.). Promoção da saúde: um enfoque interdisciplinar. Maringá, PR: Cesumar, 2012. p. 69- 83.

MESQUITA, Riovaldo Alves de. Mudanças econômicas e sociais em um Brasil que envelhece. In: MASSUDA, Ely Mitie; VELHO, Ana Paula Machado (Org.). Promoção da saúde: um enfoque interdisciplinar. Maringá, PR: Cesumar, 2012. p. 41-68.

MIOTTI, Luiz Antonio de. A engenharia civil como instrumento para a acessibilidade em ambientes construídos e a realidade de calçadas e passeios urbanos. REEC - Revista Eletrônica de Engenharia Civil, n. 4, 2012. Disponível em: <http://www.revistas.ufg.br/index.php/reec/article/view/19265>. Acesso em: 16 ago. 2013.
MOUETTE, D. Os pedestres e o efeito barreira (tese). São Paulo: EPUSP, 1998.

NANÔ, Fabiana. Número de idosos dobrou nos últimos 20 anos no Brasil, aponta IBGE. UOL Notícias, São Paulo. Publicado em 21/09/2012. Disponível em: $<$ http://noticias.uol.com.br/cotidiano/ultimas-noticias/2012/09/21/numero-de-idosos-com-mais-de-60-anos-dobrou-nos-ultimos-20-anos-aponta-ibge. htm>. Acesso em: 13 set. 2013.

NASCIMENTO, Eloísa. Prefeitura tem obrigação de indenizar por queda em calçada irregular. 28/10/2010. Disponível em: <http://www.conjur.com.br/2010-out-28/prefeitura-obrigacao-indenizar-queda-calcada-irregular $>$. Acesso em: 26 out. 2013.

RAMOS, Ademilson Tiago de Miranda. As ruas precisam de se adaptar aos idosos. Site Engenharia é. Disponível em: <http://www.engenhariae.com.br/colunas/as-ruas-precisam-de-se-adaptar-aos-idosos/>. Acesso em: 01 jul. 2013.

REIS FILHO, N. G. Quadro da arquitetura no Brasil. São Paulo: Perspectiva, 1987. 